\title{
DNA Functionalized Single-Walled Carbon Nanotubes for Electrochemical Detection
}

\author{
Chenguo Hu, ${ }^{\dagger \neq}$ Yiyi Zhang, ${ }^{\S}$ Gang Bao, ${ }^{\S}$ Yuelan Zhang," Meilin Liu, ${ }^{\ddagger}$ and Zhong Lin Wang*, \\ Department of Applied Physics, Chongqing University, Chongqing 400044, China, and School of Materials \\ Science and Engineering and Department of Biomedical Engineering, Georgia Institute of Technology, \\ Atlanta, Georgia 30332-0245
}

Received: September 6, 2005; In Final Form: September 23, 2005

\begin{abstract}
Single-walled carbon nanotubes (SWNTs) were effectively dispersed and functionalized by wrapping with single-stranded DNA (ssDNA). The ssDNA-SWNTs attach strongly on glass substrate and easily form a uniform film, making it possible for electrochemical analysis and sensing. The film was fabricated into a working electrode, which exhibited good electrochemical voltammetric properties, such as flat and wide potential window, well-defined quasi-reversible voltammetric responses, and quick electron transfer for a $\mathrm{Fe}(\mathrm{CN})_{6}{ }^{3-} / \mathrm{Fe}(\mathrm{CN})_{6}{ }^{4}$ system, indicating that the ssDNA-SWNTs film should be a good analytical electrode for electrochemical detection or sensing. This was demonstrated by highly selective and sensitive detection of a low concentration of dopamine in the presence of excess ascorbic acid.
\end{abstract}

\section{Introduction}

Due to their unique physical and chemical properties and potential applications, SWNTs have been of great interest to researchers over the past decade. ${ }^{1}$ Significant progress has been made in the characterization of both single-walled and multiplewalled carbon nanotubes, ${ }^{2-4}$ mostly concerning the properties of individual nanotubes. ${ }^{7-9}$ However, for a more complete understanding about single-walled carbon nanotubes and also for many of their potential applications, functionalization and solubilization of nanotubes are required. Different approaches have been used to address this issue, ${ }^{10-14}$ making it possible to carry out solution chemistry.

DNA is a naturally occurring polymer that plays a central role in biology. Many unique properties of DNA have inspired researchers to combine this biological material with SWNTs to explore its nonbiological applications, such as covalent conjugation $^{15}$ of DNA to oxidizing open ends of SWNTs for selfassembled molecular-scale electronic systems, noncovalent binding ( $\pi$-stacking) of DNA to side walls of SWNTs for dispersion and separation of SWNTs, ${ }^{16}$ and DNA-templated carbon nanotube field-effect transistors. ${ }^{17}$ However, few reports are available about DNA-functionalized SWNTs for applications in electrochemical analysis. Recently, Zheng and Diner reported that they used DNA - carbon nanotube (CNT) hybrids to monitor electron transfer between small-molecule redox reagents and carbon nanotubes by using UV/vis/NIR absorbance spectra. ${ }^{18}$ Here, we present an alternative strategy by using CNT film as an electrode for electroanalytic detection. We found that SWNTs could not only be thoroughly dispersed in aqueous solution, as demonstrated earlier, ${ }^{16}$ but also adhere tightly onto glass sub-

\footnotetext{
* Corresponding author. e-mail: zhong.wang@mse.gatech.edu.

† Chongqing University.

School of Materials Science and Engineering, Georgia Institute of Technology.

$\S$ Department of Biomedical Engineering, Georgia Institute of Technology.
}

strates, like paint, after being wrapped by ssDNA. Such an advantage enables us to obtain a uniform film that remains undamaged even after being dipped into an aqueous solution for a few months. Here, we report the electrochemical voltammetric properties for an electrode made from this ssDNASWNTs film, as well as detection of low-concentration dopamine in the presence of excess ascorbic acid.

\section{Materials and Methods}

As-synthesized HiPco SWNTs were purchased from Carbon Nanotechnologies Inc. (Houston, TX). Single-stranded DNA, (GT $)_{15}$, was synthesized by Integrated DNA technologies, Inc. (Coralville, IA), with a sequence of 5'-GTGTGTGTGTGTGTGTGTGTGTGTGTGTGT-3', which has been reported to most efficiently disperse SWNTs. ${ }^{16}$ Dopamine and ascorbic acid of analytical purity were purchased from Sigma-Aldrich (St. Louis, MO).

Dispersion of SWNTs by ssDNA was carried out as described previously. ${ }^{16}$ Briefly, $1 \mathrm{mg}$ HiPco SWNTs was mixed with 1 $\mathrm{mL}(\mathrm{GT})_{15}$ solution $(1 \mathrm{mg} / \mathrm{ml}$ in $10 \mathrm{mM}$ Tris, $1 \mathrm{mM}$ EDTA, $\mathrm{pH}$ 7.6) and sonicated with a cup-horn sonicator at $3 \mathrm{~W}$ for 1 $\mathrm{h}$ in an ice/water bath. The mixture was then centrifuged to remove any insoluble materials, and the supernatant was filtered through a disk membrane (with pore size of $100 \mathrm{~nm}$ ). The pellet of DNA-SWNTs on the membrane was washed with copious amounts of water to remove buffer components and unbound DNA, and the purified sample was characterized by scanning electron microscopy (SEM), energy-dispersive X-ray spectroscopy (EDS), transmission electron microscopy (TEM), and FTIR.

A glass slide $\left(0.6 \times 1 \mathrm{~cm}^{2}\right)$ was cleaned by treatment with piranha solution (concentrated $\mathrm{H}_{2} \mathrm{SO}_{4} / 30 \% \mathrm{H}_{2} \mathrm{O}_{2}$, volume ratio $7: 3$ ) at $95{ }^{\circ} \mathrm{C}$ for $30 \mathrm{~min}$. An aqueous solution of DNA-SWNTs $(0.4-0.6 \mathrm{mg} / \mathrm{mL})$ was applied to the glass slide and dried on a heat block $\left(60^{\circ} \mathrm{C}\right)$. This process was repeated several times. 


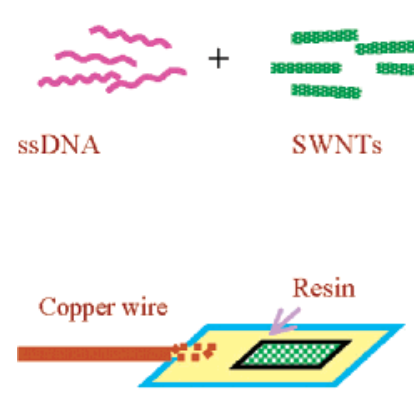

Electrode
Sonication

DNA-SWNT hybrids
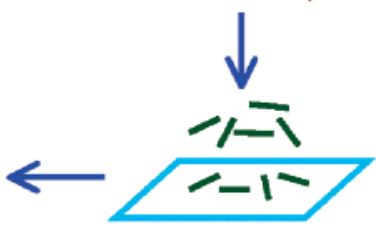

Film

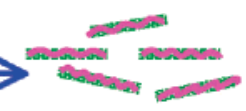

Figure 1. The fabrication process of DNA-SWNT electrode. First, ssDNA was mixed with SWNT to form DNA-SWNT hybrid, and then, the DNA-SWNT hybrids were deposited onto a glass substrate to form a uniform film, and finally, the film was welded with copper wire and mounted with resin, leaving a small nanotube area for sensing.

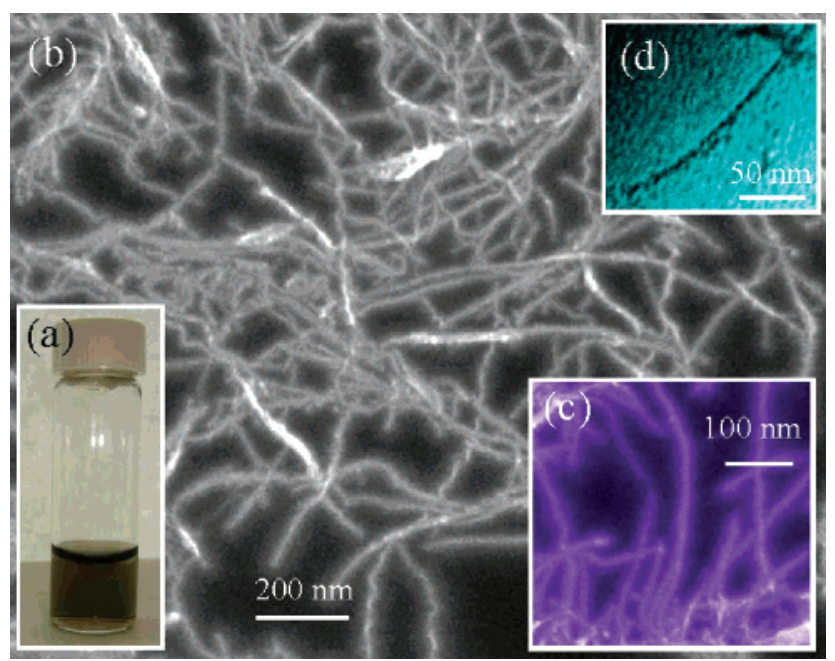

Figure 2. Images of DNA-SWNT hybrids. (a) Pictures of wellsolubilized DNA-SWNT solution; (b) SEM image of individually dispersed SWNTs; (c) enlarged SEM image; (d) TEM image, which clearly shows the shape of DNA wrapping on SWNTs.

The thickness of the final film of dried ssDNA-SWNTs is about $7 \mu \mathrm{m}$ (measured by SEM from side view), and resistivity of the film is $45.18 \Omega \mathrm{cm}$ (measured by four probe method).

A working electrode was made by welding a copper wire onto the ssDNA-SWNTs film, with silver paste. After this, the electrode was partly mounted with epoxy resin, and a small area of film $\left(\sim 0.142 \mathrm{~cm}^{2}\right)$ was left exposed, which was used to measure the voltammetric properties of the electrode, as well as to detect dopamine. The whole process to make the electrode is shown in Figure 1.

Cyclic voltammetric measurements were performed in a threeelectrode system, including the ssDNA-SWNTs working electrode, a platinum counter electrode and an SCE reference electrode. The data were recorded with an EG\&G 273A potentiostat/galvanostat interfaced with a computer. All of the reagents are of analytical purity as supplied by Sigma-Aldrich, and deionized water obtained from a Millipore water system was used throughout. All of the electrochemical experiments were performed at room temperature $\left(\sim 23{ }^{\circ} \mathrm{C}\right)$.

\section{Results and Discussion}

Purified DNA-SWNTs can be dispersed in water and form a stable solution, as shown in Figure 2a. SEM analysis indicated that SWNTs were thoroughly dispersed and existed in individual nanotubes (Figure 2b), with an average length of about $600 \mathrm{~nm}$.
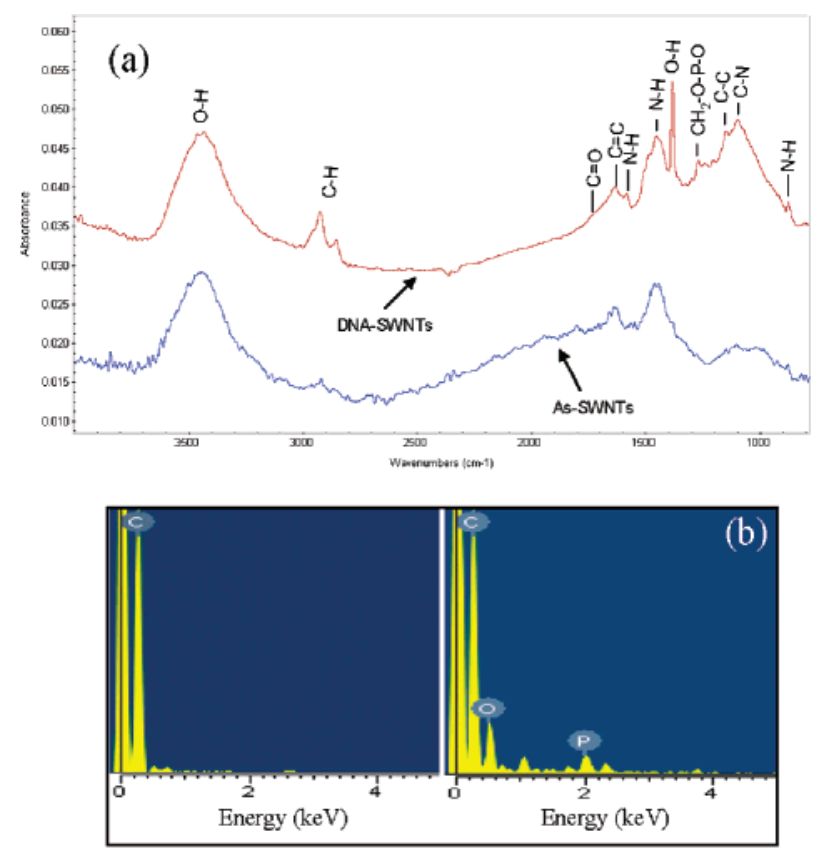

Figure 3. (a) FT-IR spectra and (b) EDS of as-produced SWNTs and DNA-SWNT hybrids.

A higher-magnification image showed a bead-string-like structure of SWNTs, indicating the wrapping of DNA along SWNT sidewalls (Figure 2c,d).

The mechanism of dispersing SWNTs by DNA can be explained by electrostatics of the DNA-SWNT hybrids. Though carbon nanotubes are electrically neutral, DNA carries lots of negative charges. So, when individual nanotubes are released by sonication, DNA binding through $\pi$-stacking charge up the nanotubes. As a result, individual nanotubes will repel each other and form a stable solution, rather than aggregating together by Van de Waals force.

To further demonstrate binding of DNA with SWNTs, FTIR spectroscopy and EDS analyses were conducted. Figure $3 \mathrm{a}$ shows FT-IR spectra of bare and DNA-wrapped SWNTs. For the DNA-wrapped SWNTs sample, the peak at $1264 \mathrm{~cm}^{-1}$ refers to the $\mathrm{CH}_{2}-\mathrm{O}-\mathrm{P}-\mathrm{O}$ phosphate group. ${ }^{19}$ The DNA-SWNTs complex results in the intensity increase or the appearance of $\mathrm{H}$-bonded $\mathrm{O}-\mathrm{H}$ and $\mathrm{N}-\mathrm{H}$ stretching vibration as well as an asymmetrical $\mathrm{PO}_{2}^{-}$vibration at $1234 \mathrm{~cm}^{-1}$, a sugar vibration at $880 \mathrm{~cm}^{-1}$, the $\mathrm{C}=\mathrm{C}$ vibration at $1640 \mathrm{~cm}^{-1}$, and the $\mathrm{C}=\mathrm{O}$ vibration at $1720 \mathrm{~cm}^{-1}$, which indicate the helix interaction of DNA with SWNT. ${ }^{20}$ The EDS analysis (Figure $3 b$ ) further confirms the existence of DNA on the SWNTs.

We found that the DNA-SWNTs hybrid could firmly attach onto a glass substrate and form a uniform film, as depicted in Figure 4. This is due to the high dispersity of DNA-SWNTs. After dispersion, the individual SWNTs have a high surfaceto-volume ratio and surface free energy, so they tend to interact with each other as well as the glass substrate to release some of the free energy while the water evaporates. The strains among any of the nanotubes to form the film are equivalent in all directions, since they are individually suspended in water. If the nanotubes are not individually suspended in water, the asymmetric strain from nanotubes will result in uneven film, which cannot adhere tightly to the glass and will easily fall off when put into solution.

The potential window is one of the most important factors for an electroanalytic electrode, and well-performing electrodes can give a good signal-to-noise ratio with a flat and wide 


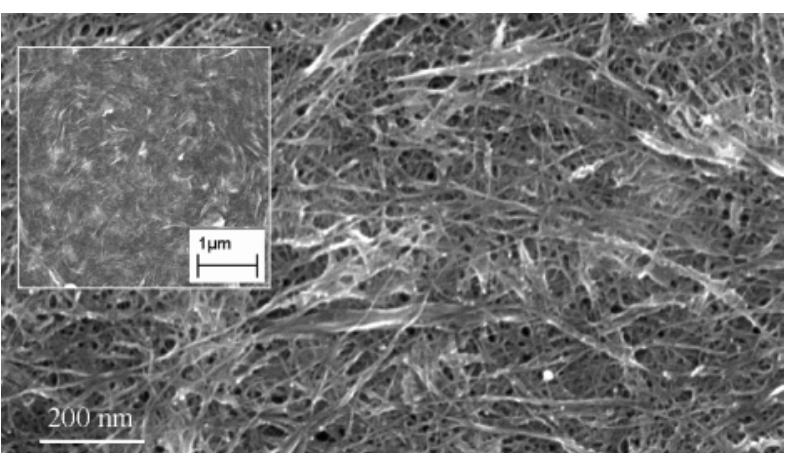

Figure 4. Topography SEM image of the ssDNA-SWNT electrode.

potential window. Figure 5a indicates that the potential window of the DNA-SWNT electrode in $0.1 \mathrm{M} \mathrm{KCl}$ is flat and wide; although the background current is a little high, no redox reaction appears in the potential window, implying this electrode may have a higher signal-to-background ratio for analytic detection.

Redox pairs are usually used to probe the quality of the electrode by cyclic voltammetry. ${ }^{21-23}$ To investigate the electronic transfer properties of the DNA-SWNT electrode, we chose $\mathrm{Fe}(\mathrm{CN})_{6}{ }^{4-} / \mathrm{Fe}(\mathrm{CN})_{6}{ }^{3-}$ as redox pairs for their voltammetric responses. In Figure 5b, the cyclic voltammograms exhibit well-defined redox reaction at potentials of 0.297 and $0.177 \mathrm{~V}$. The voltammograms are reproducible, except for the first cycle, because the starting concentration distribution of reductive/oxidative reactant near the electrode is a little different from the following cycles. From Figure 5c, we can see the peak currents increase linearly with $\mathrm{Fe}(\mathrm{CN})_{6}$ concentration, which matches the equations $I_{\mathrm{pa}}=54.75+20.76 C, r=9999$, and $I_{\mathrm{pc}}=67.05+18.35 C, r=9997$, where $I_{\mathrm{pa}} / I_{\mathrm{pc}}, C$ and $r$ are the oxidation/reduction peak current in microamperes, concentration in millimoles, and correlative coefficient, respectively. We then
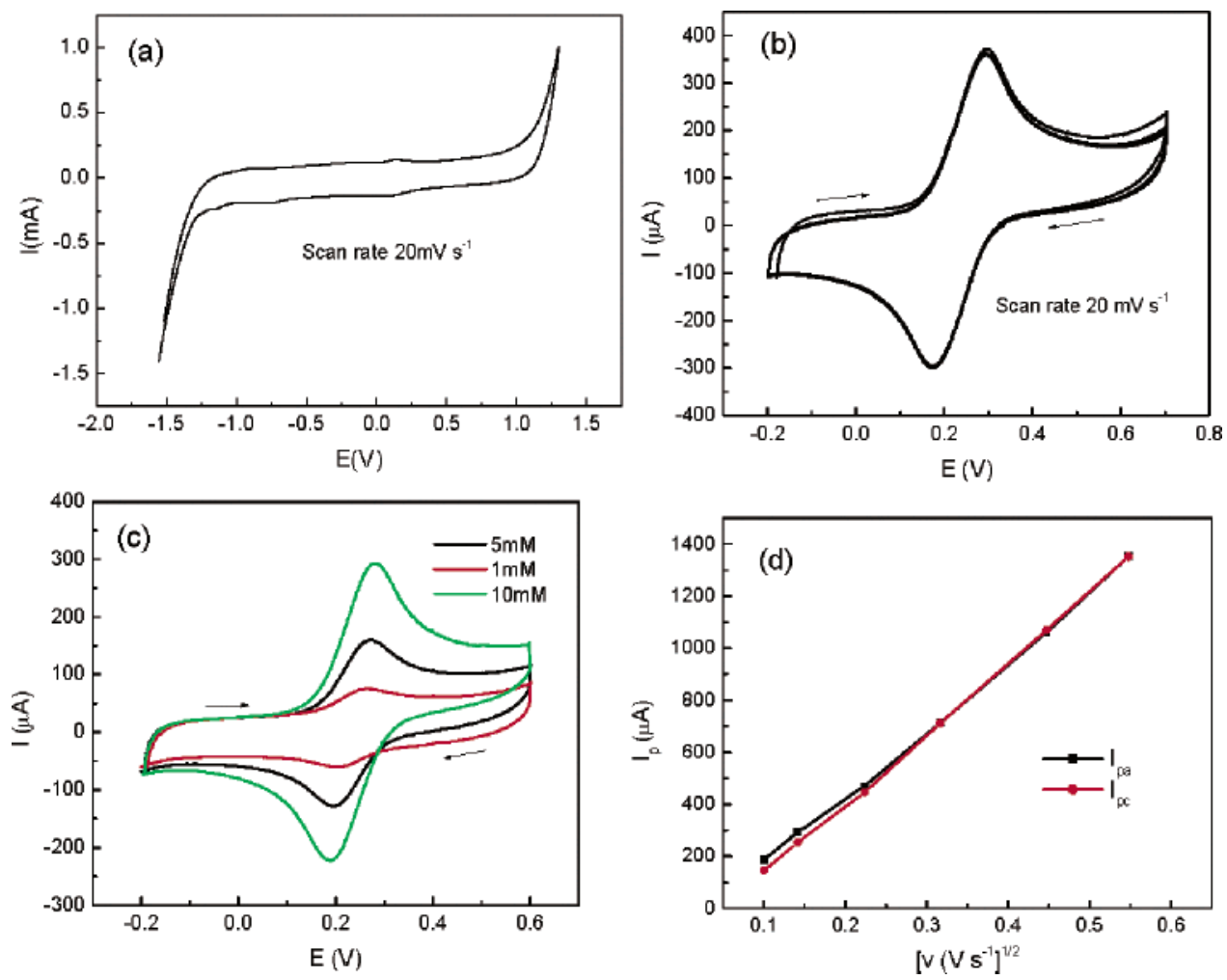

Figure 5. (a) Potential window for ssDNA-SWNT electrode in $0.1 \mathrm{M} \mathrm{KCl}$. (b) Cycle voltammogram of $10 \mathrm{mM} \mathrm{Fe}(\mathrm{CN})_{6}$ in $1 \mathrm{M} \mathrm{KCl}$ for 5 cycles. (c) Cyclic voltammograms for different concentrations of $\mathrm{Fe}(\mathrm{CN})_{6}$ in $1 \mathrm{M} \mathrm{KCl}$ at scan rate of $20 \mathrm{mV} \mathrm{s}^{-1}$. (d) Redox peak currents proportional to square root of the scan rate for $10 \mathrm{mM} \mathrm{Fe}(\mathrm{CN})_{6}$ in $1 \mathrm{M} \mathrm{KCl}$. 

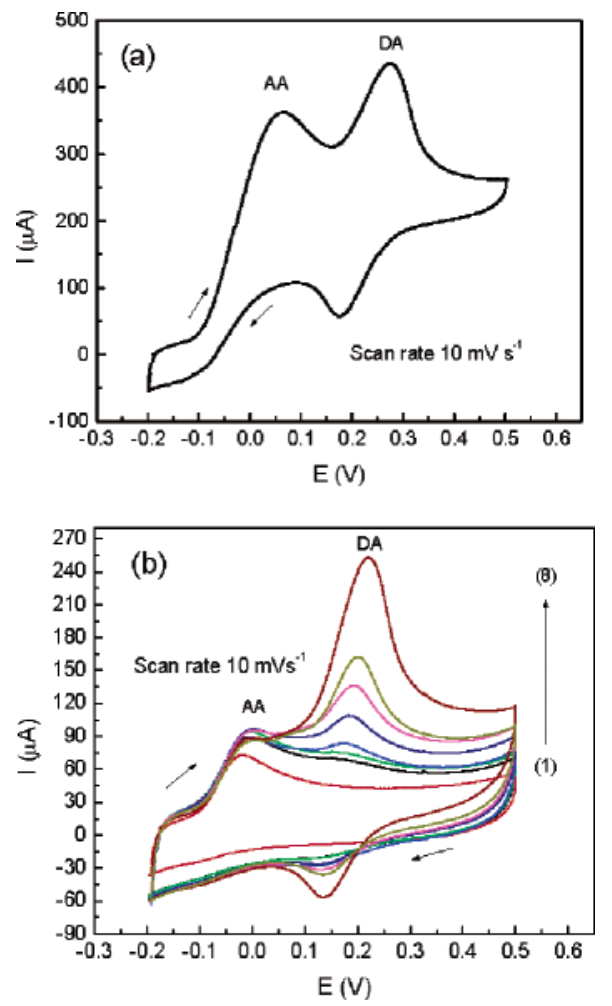

Figure 6. Cyclic voltammetric detection at DNA-SWNT electrode in $0.1 \mathrm{M}$ PBS, pH 7.0 (a) for $2 \mathrm{mM} \mathrm{DA}+20 \mathrm{mM} \mathrm{AA}$ and (b) for different DA concentration: (1) $0 \mathrm{M}$, (2) $5 \times 10^{-8} \mathrm{M}$, (3) $5 \times 10^{-7}$ $\mathrm{M}$, (4) $5 \times 10^{-6} \mathrm{M}$, (5) $1 \times 10^{-5} \mathrm{M}$, (6) $5 \times 10^{-5} \mathrm{M},(7) 1 \times 10^{-4} \mathrm{M}$, (8) $5 \times 10^{-4} \mathrm{M}$, in $2 \mathrm{mM} \mathrm{AA}+0.1 \mathrm{M} \mathrm{PBS}, \mathrm{pH} 7.0$.

addition, some of them tend to lose stability and selectivity during measurement, and some of them do not produce wellresolved voltammograms. ${ }^{28}$

Figure 6 shows results of voltammetric detection of DA using our DNA-SWNT electrode in $0.1 \mathrm{M}$ phosphate buffer solution (PBS) of $\mathrm{pH}=7.0$. Peaks for DA and AA can be clearly identified at 0.273 and $0.063 \mathrm{~V}$ respectively, with peak separation of $0.21 \mathrm{~V}$ from Figure $6 \mathrm{a}$. The change of peak current versus the concentration of DA can be distinguished, while the concentration of AA is kept constant, as shown in Figure $6 \mathrm{~b}$. The logarithmic linear fit of DA peak current versus concentration is different from lower concentration to higher concentration, which is $\log I_{\mathrm{p}}(\mu \mathrm{A})=2.13+0.04 \log C(\mathrm{M}), r=0.999$, in $10^{-6}-10^{-8} \mathrm{M}$ and $\log I_{\mathrm{p}}(\mu \mathrm{A})=2.99+0.2 \log C(\mathrm{M}), r=$ 0.995 , in $10^{-5}-10^{-3} \mathrm{M}$. However, the detection limit of DA can reach as low as $5.0 \times 10^{-8} \mathrm{M}$, demonstrating highly selective and sensitive detection of DA by cyclic voltammetry.

The electron transfer of reactants during electro-oxidation is mainly determined by the conductivity of electrode material as well as the active functional groups on its surface. Owing to their excellent conductivity, metals (such as platinum and gold), glass carbon, and graphite are the materials usually used for electrodes. However, the number of active functional groups on surfaces of these materials is limited, as a result of limited exposed area on electrode surface. For the SWNT electrode, though its conductivity is not as good as that of those materials mentioned above, it has much higher surface area, which can accommodate much more active functional groups in a given region. This will significantly enhance the rate of surfacecatalyzed reaction, which is proportional to surface coverage of functional groups. ${ }^{29}$ For a DNA-SWNT electrode, the length of SWNTs will also play a role in conductivity. Shorter SWNTs will form more contacts. hence producing a higher contact resistivity. In this paper, the SWNTs have an average length of $600 \mathrm{~nm}$ and the electrode has a resistivity of $45.18 \Omega \mathrm{cm}$. Further studies are being carried out to see the effects of SWNT length on conductivity of the DNA-SWNT electrode.

DNA is rich in active functional groups, such as amino groups, carbonyl groups, and carboxyl groups; these groups can act as media for electron transfer in redox reaction and catalyze the oxidation of DA and AA. ${ }^{30}$ As a result, the two anodic peak potentials of DA and AA are well-separated, indicating high selectivity and sensitivity of the DNA-SWNT electrode.

\section{Conclusion}

The thoroughly dispersed single-walled carbon nanotubes have been obtained by wrapping with ssDNA. The DNASWNT hybrids can be made into a uniform film, which firmly attaches onto glass substrate. With such advantages, we can fabricate a DNA - SWNT electrode and use it in solution phase. Electrochemical experiments indicated that the DNA-SWNT electrode possesses a flat and wide potential window, welldefined quasi-reversible voltammograms, and quick electron transfer for $\mathrm{Fe}(\mathrm{CN})_{6}{ }^{4-} / \mathrm{Fe}(\mathrm{CN})_{6}{ }^{3-}$, suggesting it can be used as an electrode for electrochemical analysis. Detection of a low concentration of dopamine further demonstrates high selectivity and sensitivity of this DNA-SWNTs electrode. This study opens a new application for DNA-functionalized SWNTs.

Acknowledgment. This work has been funded by NSFC (60376032), NSF, and DARPA.

\section{References and Notes}

(1) Baughman, R. H.; Zakhidov, A. A.; De Heer, W. A. Science 2002, 297, 787. 647.

(2) Charlier, J. C.; De Vita, A.; Blase, X.; Car, R. Science 1997, 275,

(3) Li, D. C.; Dai, L. M.; Huang, S. M.; Mau, A. W. H.; Wang, Z. L. Chem. Phys. Lett. 2000, 316, 349.

(4) Frank, S. P.; Poncharal, P.; Wang, Z. L.; De Heer, W. A. Science 1998, 280, 1744.

(5) Poncharal, P.; Wang, Z. L.; Ugarte, D.; De Heer, W. A. Science 1999, 283, 1513.

(6) Regan, B. C.; Aloni, S.; Ritchie, R. O.; Dahmen, U.; Zettl, A. Nature (London) 2004, 248, 924.

(7) Kong, J.; Franklin, N. R.; Zhou, C. W.; Chapline, M. G.; Peng, S.; Cho, K.; Dai, H. J. Science 2000, 287, 622.

(8) Fennimore, A. M.; Yuzvinsky, T. D.; Han, W. Q.; Fuhrer, M. S.; Cumings, J.; Zettl, A. Nature (London) 2003, 424, 408

(9) De Heer, W. A.; Bonard, J. M.; Fauth, K.; Châtelain, A.; Ugarte, D.; Forró, L. Adv. Mater. 1997, 9, 87.

(10) Chen, R. J.; Bangsaruntip, S.; Drouvalakis, K. A.; Kam, N. W. S.; Shim, M.; Li, Y.; Kim, W.; Utz, P. J.; Dai, H. J. PNAS 2003, 100, 4984.

(11) Chen, J.; Mark, H. A.; Hu, H.; Chen, Y. S.; Rao, A. M.; Eklund,

P. C.; Haddon, R. C. Science 1998, 282, 95.

(12) Strano, M. S.; Dyke, C. A.; Usrey, M. L.; Barone, P. W.; Allen, M. J.; Shan, H. W.; Kittrell, C.; Hauge, R. H.; Tour, J. M.; Smalley, R. E. Science 2003, 301, 1519.

(13) Shim, M.; Shi Kam, N. W.; Chen, R. J.; Li, Y. M.; Dai, H. J. Nano Lett. 2002, 2, 285.

(14) Mickelson, E. T.; Chiang, I. W.; Zimmerman, J. L.; Boul, P. J.; Lozano, J.; Liu, J.; Smalley, R. E. J. Phys. Chem. 1999, 103, 4318.

(15) Yanagi, H.; Mukai, H.; Ikuta, K.; Shibutani, T.; Kamikado, T.; Yokoyama, S.; Mashiko, S. Nanotechnology 2002, 13, 601.

(16) Zheng, M.; Jagota, A.; Semke, E. D.; Santos, A. P.; Barone, P.; Chou, S. G.; Diner, B. A.; Dresselhaus, M. S.; McLean, R. S.; Onoa, G. B.; Samsonidze, G. G.; Semke, E. D.; Usrey, M. Walls, D. J. Science 2003, $302,1545$.

(17) Keren, K.; Berman, R. S.; Buchstab, E.; Sivan, U.; Braun, E. Science 2003, 302, 1380.

(18) Zheng, M.; Diner, B. A. J. Am. Chem. Soc. 2004, 126, 15490.

(19) Buzaneva, E.; Karlash, A.; Yakovkin, K.; Shtogun, Y. Mater. Sci. Eng. 2002, C19, 41

(20) Dovbeshko, G. I.; Repnytska, O. P.; Obraztsova, E. D.; Shtogun, Y. V. Chem. Phys. Lett. 2003, 372, 432.

(21) Xu, J.; Granger, M. C.; Chen, Q. Anal. Chem. 1997, 69, 591A

(22) Galizzioli, D.; Trasatti, S. J. Electroanal. Chem. 1973, 44, 367. 
(23) Notsu, H.; Fukazawa, T.; Tatsuma, T.; Tryk, D. A.; Fujishima, A. Electrochem. Solid State Lett. 2001, 4, H1.

(24) Bard, A. J.; Faulkner, L. R. Electrochemical Methods; John Wiley \& Sons: New York, 2001.

(25) Zen, J. M.; Chen, I. L. Electroanalysis 1997, 7, 537.

(26) Fujishimz, A.; Rao, T. N.; Popa, E.; Sarada, B. V.; Yagi, I.; Tryk, D. A. J. Electroanal. Chem. 1999, 473, 179.
(27) Miyazaki, K.; Matsumoto, G.; Yamada, M.; Yasui, S.; Kaneko, H. Electrochim. Acta 1999, 44, 3809.

(28) Jaegfeldt, H. J. Electroanal. Chem. 1980, 110, 295

(29) Evans, J. F.; Kuwana, T.; Henne, M. T.; Royer, G. P. J. Electroanal. Chem. 1977, 80, 409.

(30) Palmisano, F.; Malitesta, C.; Centonzet, D.; Bmbonin, P. Q. Anal. Chem. 1995, 67, 2207. 